\title{
Lo individual y lo social en el Joker de Batman: el caballero de la venganza
}

\author{
Individual and social in the Joker \\ of Batman: Knight of Vengeance
}

\author{
Meritxell Plana Alsina
}

Universitat de Barcelona

Graduada en Estudios Literarios por la Universitat de Barcelona donde cursa el Máster oficial en Creación y Representación de Identidades Culturales (CRIC) con un trabajo final sobre la representación de la mujer en los cómics de superhéroes. Al mismo tiempo, cursa un grado en Psicología en la Universitat Oberta de Catalunya (UOC).

Colaboradora en la revista Caràcters (UV) y en el blog Peliomanta. Ponente en el simposio Gender and the graphic novel con la comunicación «La (de)construcción de Laurie: la androginia y la mirada del otro en Watchmen de Alan Moore».

Fecha de recepción: 15 de septiembre de 2019

Fecha de aceptación definitiva: 19 de noviembre de 2019 


\title{
Resumen
}

La separación entre Batman: el caballero de la venganza y la tradición de personajes como Batman o Joker es abismal. Para analizar dicha obra es esencial comparar la versión tradicional con la de este cómic y así proseguir con el estudio intrínseco de esta última versión. Lo más complejo de la obra es la propia creación del personaje de Joker en un laberíntico entramado de construcción social y política que llevan a una madre cariñosa a convertirse en un/a criminal con todas las implicaciones inherentes a la trama.

Palabras clave: Batman, construcción social, Joker, locura, maternidad

\begin{abstract}
The distance between Batman: Knight of Vengeance and the traditional version of Batman and Joker is abysmal. In order to analyze this comic is essential compare it with the traditional version of the characters. Then it's possible to study Batman: Knight of Vengeance intrinsically. But the most complex part of this comic is the creation of Joker character in a labyrinthine lattice of social and political construction that transforms a devoted mother to a criminal and all the implications inherent in the plot.
\end{abstract}

Key Words: Batman, Joker, social construction, madness, maternity

\section{Cita bibliográfica}

Plana Alsina, M. « Lo individual y lo social en el Joker de Batman el caballero de la venganza», en CuCo, Cuadernos de cómic, n. ${ }^{\circ} 13$ (2019), pp. 80-98. 


\section{Introducción}

Joker es uno de los villanos más habituales en los cómics de Batman, e incluso en las películas ha tenido una repercusión de suma importancia. Nos encontramos con Heath Ledger, Jack Nicholson, Jared Leto y Joaquin Phoenix encarnando al payaso de Gotham. Pero lo esencial aquí no es el peso específico de todos estos hombres encarnando al demente más notable del mundo de la viñeta, más bien lo contrario. ¿Cuántas veces Joker ha sido encarnado por una mujer? Solo una. Nos referimos al cómic El caballero de la venganza, derivado del evento Flashpoint, donde la figura del Guasón está encarnada por Martha Wayne. ${ }^{1}$

Antes de empezar el análisis de este personaje, hay que comprender el conflicto general entre Batman y Joker y ponerlo en relación con las divergencias presentes en $\mathrm{El}$ caballero de la venganza. La historia del caballero de la cruzada nace en los años cuarenta, y desde entonces se han podido ver muchas versiones del personaje; de la misma manera que han aparecido diferentes versiones del payaso de Gotham. Son muchas las discrepancias que han ido surgiendo, pero las esenciales aquí tienen su origen en el citado Flashpoint y el cambio en la historia familiar de los Wayne. Estos dos elementos comportan un cambio sustancial: los protagonistas de este cómic son Batman y Joker, pero las personas que hay debajo de la máscara no son las prototípicas.

Batman está encarnado por Thomas, en lugar de Bruce Wayne. No es un héroe; es un caballero de la venganza que no busca la heroicidad — de hecho, sus intenciones y motivaciones disienten abruptamente de las clásicas-. Es un hombre que ha perdido a su hijo y cuya motivación será únicamente vengar dicha muerte. El caso de Thomas en este cómic merece un estudio aparte, pero, como mínimo, es de justicia remarcar las implicaciones que la muerte de su hijo despiertan en su voluntad, en sus intenciones y en sus motivaciones. En una relación intrínseca nos encontramos frente a Joker, que no es un criminal demente pseudomafioso: es una representación del trauma que muestra de forma contundente las idiosincrasias que separan el Joker paradigmático del de este cómic donde, al fin y al cabo, hay un rostro perfectamente conocido escondido bajo la máscara. Martha Wayne encarna al personaje y, aunque la mujer

\footnotetext{
${ }^{1}$ Si bien no hay duda respecto a la identidad sexual de Martha Wayne, la lengua castellana presenta un problema abierto en el momento de transcribir el nombre del personaje-máscara. Hemos optado por mantener el masculino (El Joker) para no manifestar de manera abrupta y enfática el cambio de género frente a la tradición. Al mismo tiempo, en inglés se refieren al personaje como «The Joker», obviando las marcas de género y acentuando así su andrógina, que rompe con la feminidad. No hemos encontrado una opción igualmente válida en castellano; por eso, escribimos esta aclaración.
} 
desaparece para dar lugar al criminal, este giro de guion despierta unas implicaciones políticas innegables. La figura femenina es omnipresente al mismo tiempo que lo es la implicación social de dicha transformación.

Por eso, es fundamental comprender a Batman y Joker desde la confrontación entre colectivo e individualidad, lucha que evidencia las implicaciones ideológicas en la creación de los personajes. Así pues, se debe analizar la máscara de Batman y de su actuación en dialéctica con las implicaciones del comportamiento del personaje original y sus, hasta ahora, pequeñas variantes; lo mismo con Joker y las connotaciones de la creación del mítico villano en este cómic en concreto. Ambos personajes son realmente novedosos e interesantes, pero no se puede abarcar todo, por ese motivo prestaremos especial atención a la construcción novedosa que dicha versión presenta de Joker sin obviar implicaciones esenciales de Batman.

Partiendo de las mutaciones acontecidas, es esencial interpretar la locura como elemento de realidad y de construcción de una máscara que rompe con la feminidad, para explicar cómo el Joker de este cómic, más que un villano cualquiera como podría haber sido en el pasado, se ha convertido en una deconstrucción de unos ideales arcaicos que actualmente están desfasados pero que la sociedad concibe como locura. Y todo esto sin obviar un elemento esencial: la transformación de Martha Wayne en criminal enmascarada nace y muere en El caballero de la venganza.

$\mathrm{E}$ l interés que suscita esta investigación parte precisamente del análisis de personajes que rompen con la estereotipación presente en la mayoría de las obras del género, para comprender las innovaciones sociales y culturales que el cómic está extrayendo de nuestra propia sociedad y estudiar sus representaciones. Por consiguiente, ese Joker no es solo la relectura de un personaje que incluso se podría considerar arcaico, sino un/a protagonista que va resurgiendo con una visión nueva y que tiene unas reificaciones mucho más cercanas a nuestra realidad — de la forma más cruel posible-. Por ello, hemos examinado a fondo la obra trazando una relación entre texto e imagen, y manteniendo siempre abierta una perspectiva ideológica.

\section{La lucha de Gotham o las diversas formas de superar el trauma}

\section{El conficto común entre Batman y Joker}

Hay que poner de relieve, en primera instancia, la intrínseca distancia que separa la representación presente en este cómic, El caballero de la venganza, del común imaginario del conflicto entre Batman y Joker.

Si hablamos de la representación prototípica del conflicto, nos encontramos con una dicotomía más o menos marcada entre el bien y el mal. En la mayoría de los cómics, 
Batman es concebido como un héroe aceptado socialmente que trabaja con la policía para atrapar a criminales violentos como el Joker. Trabaja con James Gordon para erradicar el mal: como sujeto individual se mueve en el anonimato para actuar por encima de la sociedad y de la policía, pero participa de la colectividad, pues actúa para ayudarlos. Representa el ideal del bueno, está apartado de la civilización, pero intenta protegerla. A pesar de esta separación, Bruce Wayne - la identidad civil del caballero de la cruzada - mantiene una vida activa al mismo tiempo que lucha de forma imparable contra los villanos. Podría hacerlo de forma descubierta, pero le domina una necesidad imperante de ser el auténtico héroe: no puede existir Bruce Wayne sin Batman. Bruce se convierte en Batman porque ve morir a sus padres en plena calle y por eso representará el miedo de los que dan miedo. Es el que acecha en la oscuridad para atormentar a los delincuentes: nunca los mata, pero si les golpea y prácticamente los tortura para salvar a la ciudad de los criminales. Bruce es el heredero de una rica familia, por eso puede permitirse una vida de lujos y privilegios que usa para ser Batman. Hay que tener en cuenta que hay una dinámica totalmente individualista en el Cruzado: actúa para ayudar a la sociedad, pero lo hace también por él mismo. Bruce Wayne tiene una necesidad patológica que le lleva a enfundarse un traje y combatir el crimen de forma clandestina. Podría ayudar económicamente a la policía, pero no: tiene que ser él mismo el que salve al mundo.

Por el otro lado nos encontramos con Joker, que en las primeras representaciones se muestra como un villano arquetípico. De hecho, tiene muchos orígenes y todos ellos son inciertos. La versión más conocida hace referencia al hombre que robaba para dar de comer a los suyos - Capucha Roja ${ }^{2}$ y cayó en un pozo de productos químicos, convirtiéndose en el malo por antonomasia: el pelo verde, la piel pálida y la locura criminal. Pero Joker no tiene una doble faceta, como tienen la mayoría de los personajes heroicos o villanos: simplemente es Joker. No hay un hombre detrás de la máscara: él es el criminal, un personaje aislado de la colectividad que intenta destruirla. Y no solo eso, en muchas ocasiones, ya lo veremos, quiere convencer a Batman de que forman parte de la misma locura.

La confrontación entre Batman y Joker tiene implicaciones individuales y al mismo tiempo colectivas: Joker es comúnmente concebido como un rey de crimen, en algunos cómics incluso un capo de la mafia, y viene a ser un ideal de colectividad entre los mafiosos y criminales. Pero es una colectividad que debe verse con matices; es un

${ }^{2}$ Es un criminal que aparece en los cómics de Batman cuya identidad es un incógnito y desapareció tras conseguir un gran botín. En uno de los cómics más famosos del cruzado de la capa, El hombre tras la Capucha roja, se descubre que dicho malhechor misterioso se sumergió en un estanque de productos químicos y resurgió convertido en Joker, con sus característicos rasgos físicos y el nombre adoptado del naipe. Tal historia se retoma como hilo argumental en Batman: la broma asesina, con modificaciones argumentales, como que era un padre de familia que robaba para dar se comer a sus hijos, que lo manipulaban y que acabó cayendo por error en el estanque que lo convertiría en un criminal demente. 
conjunto que está fuera de la sociedad, está marginado y cerrado. Esta hipóstasis de la criminalidad se disuelve cuando tiene que luchar contra Batman, puesto que se trata de dos individuos que se enfrentan por encima de todo. Claro que tienen una representación concreta y propia: Joker considera que el lugar de Batman está en Arkham, ${ }^{3}$ con ellos, y por eso intenta convencerlo de que se está engañando a él mismo intentando salvar a los demás, que debe unirse a esta entelequia que es el colectivo de criminales. Batman, por su parte, se esfuerza para mantenerse de parte de la colectividad mayoritaria, pero incluso él duda de su pertenencia al lado bueno. La vinculación con el Joker es inevitable: tienen motivaciones diferentes, voluntades diferentes, pero siempre acaban hiriendo a otras personas, y acaban destruyendo de igual manera la ciudad de Gotham.

\section{El conficto en $\mathrm{El}$ caballero de la venganza}

Si analizamos ahora la presencia de estos dos personajes en El caballero de la venganza vemos que hay muchas variaciones. Para empezar, el imaginario que hay detrás varía de forma drástica. El Batman de este cómic no es Bruce Wayne, sino que es su padre, Thomas. Para entender esto, nos tenemos que remontar a la historia de los Wayne ${ }^{4}$ y el evento de DC conocido como Flashpoint. ${ }^{5}$ Una vez entendidos estos dos fenómenos, comprendemos que Bruce Wayne no puede ser Batman porque muere en el atraco; así pues, será su padre el que se convierta en el cruzado de la capa. Pero no adopta la visión de salvar la ciudad de la familia, como hacía Bruce, sino que se lo toma como una lucha personal para vengarse. Primero mata al asesino de su hijo y luego prosigue con una masacre de asesinos. Ya no hay una relación entre individuo y colectividad, sino que se separa totalmente de los mortales para llegar a ser el murciélago vengador. Vamos a repetirnos: Thomas merecería un trabajo propio para analizar todos los detalles de su construcción como Batman, pero no podemos no hacer referencia a esta pérdida que le construye como justiciero al mismo tiempo que destruye su doble representación social.

${ }^{3}$ Lo hace en Asilo Arkham de Morrison y McKean. Arkham, por cierto, es el mundo de la locura.

${ }^{4}$ La historia de los Wayne, representada de forma amplia en muchos cómics o incluso en las películas, nos cuenta que Bruce se convirtió en Batman porque de pequeño perdió a sus padres en un atraco, y a raíz de este accidente y de la caída en un pozo que se convirtió en fobia a los murciélagos, creó su doble identidad. La pérdida de sus progenitores a mano de la fuerte delincuencia de la ciudad — que la pareja quería erradicar - despertó en el joven Bruce una necesidad casi patológica de convertirse en el ser que limpiara las calles de criminales, y que mejor que adoptar su propio miedo para convertirse en el miedo de los que dan miedo. Aquí se presenta una versión muy reducida de la historia de Bruce —además, a lo largo de los años se ha descubierto que hubo elementos políticos detrás del asesinato de los Wayne, pero partiremos de este pequeño resumen para construir nuestra narración, puesto que no es necesario saber más.

5 Flashpoint es el fenómeno que creó el personaje de Flash al volver al pasado para salvar a su madre, asesinada por otro velocista. Al cambiar el pasado creó una especie de efecto mariposa al revés, modificando el trascurso de la historia. El elemento innovador que nos interesa es el siguiente: los que mueren en el atraco de los Wayne no son los padres, sino Bruce. Así pues, la historia del personaje de Batman da una vuelta de forma radical. 
La pérdida de la familia — no solo se trata de la muerte de su hijo, sino que también ha perdido a su mujer que primero entra en depresión y finalmente se acaba convirtiendo en Joker- le llevan a la desesperación: no ha cumplido el rol social de protector, ha fallado en su misión de ser padre y ser marido. Eso —o, como mínimo, sobre todo eso- le lleva a la locura - una locura que comparte en cierta medida con Joker-, a la capa y a la violencia incontrolada contra todos los delincuentes de la ciudad. El Batman de Thomas se construye a través de la pérdida y de la necesidad de recuperar aquello perdido: no puede recuperar a su hijo, así que recupera el miedo de este - los murciélagos- y se convierte en aquellos que aterraron y mataron a su pequeño. No puede ser un padre, pero será un vengador. Otro elemento esencial en la construcción de Thomas Wayne como Batman proviene de la dualidad de su máscara: Se enmascara para convertirse en el Murciélago y conseguir así todo aquello que se ha propuesto, es decir, acabar con el crimen en la ciudad y matar a todos aquellos que propiciaron la muerte de su hijo. Pero ¿es la única máscara que viste? A lo largo de la historia de Batman se ha teorizado mucho sobre la posibilidad de que la máscara real del personaje se encuentre realmente en el hombre y no en el murciélago. En este Batman en concreto, sin duda, nos encontramos ante un Thomas que viste la máscara de padre, de hombre, de ciudadano modelo. Pero en realidad ya no queda nada de esta persona, el Thomas bueno muere con su hijo y lo único que queda tras el atraco es una máscara vacía que solo se completa cuando se viste de murciélago y acecha las calles de la ciudad en busca de criminales a los que castigar. En la película de El caballero oscuro: La leyenda renace, ${ }^{6}$ Nolan ya plantea esta idea de un hombre que en realidad viste la máscara del ciudadano, cuando su verdadero rostro es el que acecha en la oscuridad. Cuando el Batman de Nolan se quita la máscara se convierte en una cáscara vacía, que no vuelve a estar completa hasta recuperar la identidad del murciélago. En el caso del Batman de Thomas, no podemos ver el abandono de la máscara para comprender este vacío, pero tras la pérdida de rol familiar asignado socialmente, comprendemos que la identidad que queda en Thomas no es más que el de la venganza, es decir, el de Batman. Posteriormente hablaremos de la máscara en el Joker de Martha Wayne, pero ya podemos adelantar que ambos presentan una máscara simbólica que proviene de esta pérdida y que sin duda radica en lo social. Pero las máscaras que deciden vestir son sustancialmente diferentes.

La representación del Joker es, si cabe, más compleja, porque no se trata de un modelo tópico de villano con pasado ambiguo, sino que nos encontramos ante la creación de un personaje destrozado por la sociedad y por el duelo. El monstruo - que no es tal- de este cómic es Martha Wayne, que tras la muerte de su hijo y las imposiciones sociales y familiares pierde la cabeza y se convierte en Joker. Pero no es algo tan sencillo: iremos viendo poco a poco todas las implicaciones de su locura de realidad y de su creación como personaje.

${ }^{6}$ Nolan, C. El caballero oscuro: La leyenda renace [film]. Coproducción Estados Unidos-Reino Unido, Warner Bros / Legendary Pictures, 2012. Guion de Christopher Nolan y Jonathan Nolan. 


\section{Hacia una lectura individualista de Batman: el caballero de la venganza}

\section{¿Quién es el caballero de la venganza? La representación de la voz individual opuesta a la colectiva}

Nos encontramos con una representación de Batman dispar a la habitual. No es Bruce, sino Thomas Wayne; no es un salvador sino un torturador y un asesino de asesinos y criminales. No pretende salvar la ciudad, sino que se encuentra en un estado de venganza constante y progresiva por la muerte de su hijo. Su primera víctima es el asesino de su hijo, pero seguirá limpiando la ciudad. Es una forma autoimpuesta de duelo, una cruzada personal. Lo hemos visto antes: es la forma que tiene de redefinirse dentro de un juego de roles. Dado que ya no puede ser padre - ni marido- se creará un nuevo imaginario en el que, idílicamente, salva a la ciudad del crimen, aunque lo haga matando. Si alguien hubiese erradicado el mal de la ciudad, su hijo estaría vivo, su mujer no sería una criminal demente y él no se vería obligado a cumplir una misión como la que se ha impuesto. Si la función del Batman de Thomas es la de erradicar el mal es porque no ha podido ser aquello que socialmente se le exigía, es decir, un padre y un marido salvador: entonces, su condición se modificará y se transformará en Batman como vengador y justiciero. Se vestirá la máscara de hombre durante el día y, durante el amparo de la noche, será aquello en lo que se ha convertido: el murciélago vengador.

Así pues, no lo podemos llamar héroe: es un justiciero en una lucha individual, y la sociedad no lo acepta. Tampoco pretende ser de otra manera: tiene una posición radical y opuesta a la colectividad; causa destrucción y dolor a su paso. Batman, comúnmente, es visto como un héroe oscuro, pero un héroe, al fin y al cabo. En este cómic, por el contrario, la gente le tiene miedo: cualquiera puede ser víctima del Murciélago, puesto que en Gotham todo el mundo ha cometido crímenes. Y eso es precisamente lo que quiere: él ya no puede ser aquello que la sociedad le imponía que fuera, es decir, un padre bondadoso y un marido cariñoso, así que tras la pérdida de su hijo y de todos los ideales que se había formado alrededor de su familia se convertirá en el terror de los criminales que le han quitado a su familia y en alguien malvado a ojos de la sociedad, puesto que no cumple el rol asignado. Sin embargo, la construcción de este personaje es mucho más compleja y aquí solo estamos dando pinceladas porque un análisis más específico nos obligaría a desviar la mirada de nuestro tema central.

\section{¿Quién es el Joker? ¿Cuál es su motivación? La individualidad hecha trauma}

Hay una serie de peculiaridades que caracterizan la mayoría de las representaciones del Joker, y una de las más importantes es la inexistencia de la doble cara del personaje. El Joker, en todo su imaginario, borra la representación de la persona que fue antes de su creación — si es que se conoce-. ¿ Recordáis cuando hablábamos de la máscara 
de Batman? El Joker, en todas sus versiones, va un paso más lejos y desdibuja la imagen que había antes de la creación del monstruo. En el caso de Batman el hombre es una máscara, en el caso del Joker, esta representación es directamente eliminada.

Pero la locura del personaje no debe tomarse a la ligera, porque está lo suficientemente cuerdo como para ver, a su vez, la locura del mundo. Todas sus representaciones muestran «varias facetas del ser humano, [porque] no es un monstruo sino un ser muy humano, peligrosamente humano». ${ }^{7}$ Comprendemos que detrás de su máscara, siempre hay un rostro tremendamente humano, lleno de las cicatrices, el dolor y la rabia que caracterizan al personaje, ${ }^{8}$ que dan forma a Martha como madre que ha perdido a su hijo y con él la cabeza —algo parecido, aunque en distintos términos, podríamos decir que le ocurre a Thomas.

El Joker que aparece en El caballero de la venganza no es un criminal que enloquece: es una madre a la que han impedido vivir el duelo y que acaba por perder la cabe$z a$. Ponemos esta expresión en cursiva porque, tal y como veremos en el siguiente apartado, esta lógica deformada no es una pérdida de consciencia, sino más bien la adquisición de la capacidad de discernir el auténtico rostro del mundo. Martha, física y emocionalmente, es un personaje lleno de cicatrices, tal como dice Navarro, y eso la hace peligrosa en muchos aspectos. ${ }^{9}$

A pesar de la similitud clara en la locura de realidad, hay varias diferencias entre el Joker tradicional y el de Martha Wayne. En primer lugar, este último deja claro quién era antes de ser el Bufón: no puede ser las dos cosas a la vez, pero existe un claro referente. El Joker ya no es Martha, no cohabitan — como sí hace Thomas- pero sabemos quién es. Y, en segundo lugar, la transformación de Martha no es producto de un elemento externo, como puede ser un producto químico, sino que se deriva de una imposición patriarcal y social. Sí, ella se convierte en el personaje por el homicidio de su hijo, pero también por la prohibición social — y de su marido- de vivir un duelo autorregulado por tal pérdida. Su marido llega a decirle: «Han pasado meses, Martha. [...] Ha muerto, tienes que aceptarlo. Yo también le añoro... Y añoro tu sonrisa». ${ }^{10}$ Así, le impone la urgencia de recuperarse —y recuperar la sonrisa, que llegará a ser el símbolo del Joker-. Martha es una construcción colectiva que se vuelve radicalmente individual. La motivación que conlleva la transformación es totalmente distinta a la del Joker canónico. Como madre y como portadora de pérdida, debe desaparecer para que desaparezca la presión social; así aparece el Joker, aquel capaz de hacer todo

\footnotetext{
7 Navarro Páez, J. ¿QQuieres saber cómo me hice estas cicatrices? Análisis autobiográfico del Joker [Trabajo de Grado]. Pontificia Universidad Javeriana, Bogotá, 2014, p. 97. Disponible en https://repository. javeriana.edu.co/handle/10554/14775

8 Ibid., p.98.

9 Idem.

${ }^{10}$ Azzarello B. y Risso, E. El caballero de la venganza. Barcelona, ECC Ediciones, 2012.
} 
lo que ella es incapaz de hacer: retar a la sociedad, llevar la contraria a Batman — su marido-, incluso conspirar para matar niños. Y este es un acto revelador: la sociedad corrupta de Gotham le quita a su hijo mientras ella es Martha, así que, tras convertirse en Joker, corta el cuello a Gordon ${ }^{11}$ y monta una representación teatral que culminará con Batman matando a un niño inocente. Aquí se hace presente la demencia del mundo que la caracteriza: todos están corruptos, todos pueden matar a niños.

Su apariencia física también se modifica, asemejándose a representaciones anteriores del Joker en algunos puntos, pero separándose de forma radical de la feminidad que ella encarnaba: lleva ropa socialmente concebida para hombre, usa el maquillaje para remarcar su ruptura con el binarismo y su neurodivergencia en lugar de su feminidad e incluso se usa el neutro para hablar de ella cuando es el Joker.

La individualidad como encarnación de la ruptura con la normatividad está muy presente en nuestros días. Puede verse reflejada en canciones como «Bad guy» de Billie Eilish, donde se muestra la deformación de la feminidad heteronormativa muy parecida a la que muestra el Joker de Martha Wayne. El alejamiento de la normatividad y la carga de la represión aparece también en otras versiones del Joker que se han llevado al cine: como el de Heath Ledger (El retorno del caballero oscuro) o el de Joaquin Phoenix (Joker).

\section{Diferentes voces individuales y diferentes oposiciones entre individuo y colectivo}

Los protagonistas de nuestra obra divergen de forma marcada de la representación clásica; y esta distinción tiene un marcado origen en ambos. Si, por un lado, Thomas se convierte en un Batman que mata y busca venganza por la pérdida y Martha en una madre enloquecida y asesina, por el otro, la alteración cronológica lleva a que se desdibuje la frontera entre el bien y el mal. Los que deberían estar vivos están muertos y viceversa. El joven Bruce muere y ellos viven, y todo lo que hagan a posteriori será, en realidad, un cúmulo de errores que los lleva a asumir su naturaleza de monstruos.

Y de esa manera se produce la división radical entre el individuo y la colectividad. Batman no está socialmente bien visto y no quiere estarlo: solo quiere venganza. ¿Para qué querría la aceptación de una sociedad que ha permitido que su hijo muera, de una sociedad que permite la existencia de criminales de tal calibre? Y la venganza suprema la alcanza al final de la obra, sacrificándolo todo para volver a cambiar la

11 Este hecho es esencial puesto que James Gordon, a lo largo de todo el trayecto que han vivido los cómics de Batman, representa la bondad: es aquel que lucha por limpiar de corrupción a la policía y que se desvive por acabar con el crimen en Gotham. Que él muera degollado por la locura de Joker — que es la del mundo- es irónico al mismo tiempo que ilustrativo, si hablamos de la locura de realidad. 
línea temporal consiguiendo así que su hijo se salve y ellos mueran. Aquí hay una primacía absoluta de la voluntad individual: no tiene en cuenta a los demás, no sabe qué pasará con toda esa gente si cambia la historia, y no le importa. Ya no es un héroe, ni pretende serlo. La voluntad absoluta al final de la obra, por parte de los dos protagonistas, es clara: volver a ser padres, recuperar el rol perdido, la esencia que perdieron al dejar de ser padres - con las implicaciones de género inertes en dichas categorías - para convertirse en seres que han enterrado a su hijo y cuya única opción es oponerse a la sociedad que los ha creado como monstruos y devenir criminales.

El personaje de Martha Wayne como Joker podría ser calificado de todavía más complejo, si cabe, porque tiene unas implicaciones de género que no habían aparecido nunca relacionadas con el payaso de Gotham. Este personaje debe ser entendido en términos teóricos para comprender la voluntad individual y la vinculación con la sociedad que hay detrás del único Joker que se ha representado como «mujer». Enmarcamos el género entre comillas, puesto que, en realidad, hay una omisión voluntaria de este. De la misma manera que hay una prominente feminidad relacionada con Martha Wayne como madre, que se puede ver en la imagen y en la exaltación de los elementos propios de la feminidad a partir del dolor, se obvian de forma magistral sus elementos genéricos cuando es el Joker. Algo parecido podemos ver con Thomas: en su representación como padre está caracterizado por un rol muy marcado, un hombre de negocios y un padre de familia, mientras que en su asunción del rol de murciélago es amparado únicamente por el negro del traje, que sería una referencia al luto, y el rojo del símbolo, que sin duda se refiere a la sangre de los criminales caídos. Ya no es un hombre de negocios y padre de familia: ha perdido este imaginario para ser solo Batman.

Si volvemos a Martha, vemos que la distinción entre la representación del Bufón de esta y la tradicional se encuentra en un punto clave. Al inicio del cómic, se presenta como una madre devota, pero Bruce muere en un atraco en el que ella está presente. A pesar de su presencia en el atraco, Martha no está con su hijo en el momento final, puesto que es obligada por su marido a salir corriendo en busca de ayuda, y cuando regresa es demasiado tarde. Esto marca su trayectoria futura como madre y como mujer: tiene que deconstruirse para proseguir porque la sociedad no le permite vivir el luto y superarlo. Por eso, tiene que separarse de la maternidad y del trauma de la pérdida para convertirse en una criminal: entonces es cuando se marca una sonrisa en la cara y se transforma en el Joker, obligándose a sonreír ante la destrucción y la muerte de la sociedad.

$\mathrm{Su}$ transformación es uno de los elementos más complejos de toda la obra. No se trata de una transición simple y llana entre el bien y el mal, sino que Martha transita en una ambigüedad de grises que caracteriza, precisamente, el tono de la sociedad. En el momento en el que ve morir a su hijo, un acto que es en realidad producto de 
una situación de injusticia generalizada, se acaba convirtiendo en el reflejo de esta sociedad enloquecida. Teóricamente, cuando el Joker aparece todo lo que el sujeto había sido anteriormente desaparece. Aquí no desaparece del todo, hay una fuerte marca que tiñe toda la obra y que reaparece al final. Pero la sociedad no hace más que recordarle que su hijo ha muerto y que tiene que superarlo y volver a sonreír. Irónicamente, cuando el dolor se apodera de ella, se marca una sonrisa en la cara y le dice a su marido: «Lo entiendo, Thomas... ¿ ilo ves? Estoy sonriendo». ${ }^{12} \mathrm{Y}$ es con este acto con el que se desvincula totalmente de los demás (¿de la realidad?), deja de ser madre y mujer para convertirse en un ser autónomo. Y esto se puede relacionar de forma intrínseca con el planteamiento sobre la máscara de la feminidad, que según Rivière se usa para esconder la masculinidad y evitar las represalias sociales inherentes a la idea de tener rasgos masculinos siendo mujer. ${ }^{13}$ Martha se construye físicamente una máscara de maquillaje que emula directamente a la propia idea de antifaz. Pero al mismo tiempo es una careta más humana, si retomamos el planteamiento de Joker como un ser «peligrosamente humano». ${ }^{14} \mathrm{La}$ cara del bufón es una representación hecha con maquillaje y heridas, que rompe con la feminidad forzada que representa la vida de la Martha-madre para entrar de lleno en una idiosincrasia individual que parte de una construcción puramente social. Es decir, Martha es la radicalización individual y violenta de una voluntad social de construir a la mujer como madre sumisa y esposa devota.

En esta transformación podemos ver una estrecha relación con la actuación que hizo sobre el mismo personaje Heath Ledger en El retorno del caballero oscuro. ${ }^{15}$ Díez Balda sostiene que el cómic, en muchas ocasiones, es deudor del cine ${ }^{16} \mathrm{y}$ en estos dos Jokers se puede ver claramente. La película se estrenó años antes, pero estéticamente hay un parecido innegable entre los dos personajes, e incluso podemos encontrarnos con algunas referencias textuales a cómo Joker se hizo los cortes de la cara. El villano de la película da varias explicaciones sobre cómo se los realizó, pero la que más nos interesa es la que se cuenta en el siguiente fragmento extraído de la película:

¿Quieres saber cómo me las hice? [...] Estaba casado. Era muy guapa, como tú. Me decía que me preocupaba demasiado, que tenía que sonreír más. Le gustaba el juego y se endeudó

${ }^{12}$ Azzarello B. y Risso, E. Op. Cit.

${ }^{13}$ Rivière, J. La femineidad como máscara. Athenea Digital, 2007, pp. 219-226. Traducción de Adriana Velásquez y María Ponce de León. Disponible en http://psicologiasocial.uab.es/athenea/index. php/atheneaDigital/article/view/374/335

${ }^{14}$ Navarro Páez, J. Op. cit., p. 97.

${ }^{15}$ Nolan, C. El caballero oscuro [film]. Coproducción Estados Unidos-Reino Unido, Warner Bros / Legendary Pictures, 2008. Guion de Christopher Nolan, David S. Goyer y Jonathan Nolan.

${ }^{16}$ Dí Ez BALDa, M. A. La imagen de la mujer en el cómic: Cómic feminista, cómic futurista y de ciencia-ficción. Universidad de Salamanca, Salamanca, 2004, p. 4. Disponible en https://www.amites.org/sites/default/files/pdf/publicaciones/antonia diez balda 2004.pdf 
con quien no debía. Un día le rajaron la cara. Y no teníamos dinero para una cirugía. Ella no podía más. Yo quería volver a verla sonreír. Quería que supiera que no me importaban sus cicatrices. Así que me metí una cuchilla en la boca y me hice esto yo solito. ¿Y sabes qué? Ella no podía ni mirarme. Me dejó. Ahora le veo la gracia. Ahora estoy siempre sonriendo. ${ }^{17}$

Aunque la referencia entre las dos obras no siempre es clara, en ambos personajes hay un componente familiar que lleva a la automutilación, y este elemento es el que despierta la personalidad del Joker. El de Heath Ledger se corta para hacer feliz a su mujer, que está triste; Martha Wayne lo hace para hacer feliz a su marido, que no quiere verla afligida. En ambos hay una necesidad de encontrar la felicidad perdida y esto les convierte en monstruos, pero solo son un reflejo de la sociedad, unos locos que no se pueden integrar y por eso se les asigna ese nombre. Tanto el Joker de El caballero de la venganza como el de El retorno del caballero oscuro son personajes que comprenden la situación que viven, de hecho los ha sobrepasado, y sonríen ante la atrocidad que les producen y que producen, creando así una representación de la realidad. Algo parecido podemos entender en el Batman de Thomas Wayne, de una forma drásticamente distinta. Batman, igual que estos dos Jokers, es concebido socialmente como un monstruo puesto que ha sido incapaz de cumplir su rol, no ha salvado a su familia, no ha sucumbido a la voluntad social y se ha vuelto radicalmente individual. Al igual que los Jokers, el Batman de Thomas se ha convertido en una abominación que ansía la felicidad, pero no la encuentra en la destrucción sino en la venganza. Y solo la hallará al final de la obra, cuando urda un plan para cambiar la línea temporal y salvar así a su hijo de morir en el atraco — aunque eso le cueste su vida y la de Martha.

El 4 de octubre se estrenó la película Joker, ${ }^{18}$ protagonizada por Joaquin Phoenix, que muestra una construcción cruel y peligrosamente humana del personaje, en los términos de Navarro. ${ }^{19}$ La representación de ambos bufones se centra en los elementos sociales y los componentes culturales que despiertan al personaje-máscara, bajo el filtro interpretativo de locura de realidad. A pesar de sus similitudes, también hay muchas variaciones: el Joker de Phoenix alimenta una locura de realidad que le viene desde la infancia, es la radicalización de un trastorno gestado durante años de abusos y vejaciones, mientras que el de Martha se centra en la radicalización que supone la pérdida. La segunda construcción es mucho más brusca y no analiza de forma tan profunda el componente social - que está claramente presente pero que no se expone de una forma tan visual.

Un reflejo parecido de la locura de realidad, insistimos, se puede ver en la canción — y sobre todo en el videoclip— «Bad guy» ${ }^{20}$ de Billie Eilish. Un ser que se comporta

17 Nolan, C. (2008). Op. cit.

18 Phillips, T. Joker [film]. Estados Unidos, Warner Bros, 2019. Guion de Todd Phillips y Scott Silver.

19 Navarro Páez, J. Op. cit., p. 97.

${ }^{20}$ Eilish, B. «Bad guy», en When We All Fall Asleep, Where Do We Go? [CD]. Los Ángeles, Interscope 
como un loco, de la misma manera que es percibida como loca Martha Wayne en su representación. Se muestran, ambas, como oposiciones a la norma; y eso las convierte en seres que hablan sin tapujos de la inconsistencia del mundo que las rodea y que ellas mismas representan.

El Joker ya es lo opuesto a Martha; hace todo aquello que ella sería incapaz de hacer: retar a Batman, aterrorizar la ciudad, mostrar la crueldad del mundo. Por eso, no pueden existir las dos identidades al mismo tiempo. La mujer representa la maternidad y la construcción social impuesta y normativa; su representación es incapaz de convivir con esto, y se encarga de destruir todo lo que su viejo yo significaba. La diferencia entre estas dos caras de una misma moneda nace en la visión que la sociedad tiene de la mujer y el desgarro de este ideal heteronormativo.

Sin embargo, es esencial entender la tradición del personaje. Segura plantea que el Joker es el bufón que se burla del rey, el que dice lo que está mal porque juega con la dicotomía entre lo bueno y lo malo. ${ }^{21} \mathrm{Al}$ mismo tiempo, sostiene también que el título de loco le es asignado por una sociedad que no puede describirlo y por eso es incapaz de entender que la realidad del Joker está en total concordancia con la del mundo. ${ }^{22}$ Así, pues, podemos entender mejor a Martha si la analizamos desde la visión de la muerte de Bruce y la represión social que la obliga a interpretar un papel que ya no la representa, puesto que ya no es madre, ni sumisa ni devota. El conocimiento que ha adquirido la ha vuelto loca, en el sentido de Segura. Así pues, por mucho que digamos que el Joker de Martha Wayne es una construcción radicalmente individualista, es al mismo tiempo totalmente social, puesto que tiene una relación enfermiza con la locura de la realidad, que la construye como personaje.

Si volvemos a los planteamientos de El retorno del caballero oscuro nos tendremos que detener en una de las afirmaciones más celebres de la película: «Hay gente que no busca nada lógico, como dinero. No puedes comprarlos, intimidarlos, convencerlos ni negociar con ellos. Hay gente que solo quiere ver arder el mundo». ${ }^{23}$ Con estas frases Alfred, el mayordomo de Bruce Wayne, hace referencia a la demencia que caracteriza el Joker de Heath Ledger. En el cómic de El caballero de la venganza hay una formula similar con el Joker de Martha Wayne: no quiere nada material, solo quiere mostrar la

Records, Darkroom Records, 2019.

${ }^{21}$ Segura Jaubert, J. M. «De Derrida a Bajtín: Deconstruyendo la Figura Heroica de Batman y su antagonista el Joker, y la relación de este último con la Historia de la Risa», p. 8, 2011. Disponible en https://www.academia.edu/3796361/De Derrida a Bajtin Deconstruyendo la figura heroica de Batman y su antagonista el Joker y la conexión de este último con la Historia de $\underline{\text { la_Risa }}$

22 Segura Jaubert, J. M. «E1 Joker y su reescritura: desde el Tarot a The Dark Knight». Tebeosfera, 2. ${ }^{a}$ época, n. 10 (2012). Disponible en: https://www.tebeosfera.com/documentos/el joker y su reescritura desde el tarot a the dark knight.html

${ }^{23}$ Nolan, C. (2008). Op. cit. 
locura del mundo a través de la suya propia y, en cierta medida, eso significa destruir la realidad. Presenta una necesidad patológica de actuar y reaccionar violentamente contra la sociedad porque esta la ha hecho asi, la ha vuelto tal y como es. Esto se puede relacionar con la interpretación de Valencia:

Las mujeres, junto a todos aquellos sujetos entendidos como subalternos o disidentes de las categorías heteropatriarcales de normalidad y funcionalidad, hemos vivido en lo gore a través de la historia. [...] La violencia extrema, tanto física como psicológica [...] ha sido parte de nuestra cotidianidad, de nuestra educación. ${ }^{24}$

Martha se ha educado en la violencia implícita de la sociedad heteropatriarcal y por eso renace como Joker y reacciona con agresividad a la violencia. La agresión crea al Joker, en tanto que Martha como madre y como esposa pierde su funcionalidad. Además, la sociedad pretende que siga actuando a partir de unas normas que ya no la representan y ella no puede adaptarse: reacciona agresivamente a la violencia que le imponen y se convierte en un retrato de la sociedad.

La lucha de Valencia se puede relacionar con Witting y la representación de la mujer como alteridad. ${ }^{25}$ Martha, como mujer, forma parte de la alteridad; pero el Joker da un paso más adelante y se convierte en el Otro absoluto, en un sujeto tan incomprensible para la sociedad que incluso el mismo Batman denomina monstruo. La sociedad la crea para luego repudiarla.

Al final de la obra parece haber una disgregación en la barrera entre Joker y Martha. Esta última descubre que es posible cambiar la línea temporal: podría conseguir que su hijo volviera a vivir sacrificando su vida y su cronología. La necesidad maternal de ella borra el marcado rastro del Joker para volver a la norma. La obra muestra de forma gráfica este desdibujo: la máscara se rompe, la pintura de su cara se empieza a borrar y parece estar volviendo el rostro de feminidad - en la imagen parece estarle volviendo la belleza, a pesar de los cortes de las mejillas.

Pero hay una imposibilidad marcada en esa vuelta a la maternidad: Bruce, en la cronología clásica, se convierte en Batman. Ella, al haber sido Joker, no puede negarlo - en tanto que ya lo ha sido- y no puede vivir en un mundo en el que su hijo se convierta en Batman. Su maternidad no permitiría ese desequilibrio. En la lucha interna entre la parte que representa a la madre y la que ilustra al Joker gana el criminal. El bufón aparece como crítica a la sociedad represiva que prohibe a Martha vivir su

${ }^{24}$ Valencia, S. «Transfeminismo(s) y capitalismo gore», en Transfeminismos: Epistemes, fricciones y flujos. Editorial Txalaparta, 2013, p. 110.

${ }^{25}$ Witting, M. «El pensamiento heterosexual», en El pensamiento heterosexual y otros ensayos. Barcelona y Madrid, Egales, 2010, p. 53. Traducción de Javier Sáez y Paco Vidarte. 
duelo, y por mucho que tenga la posibilidad de devolver la vida a su hijo, ya conoce la locura de la realidad y no puede obviarla. Además, Martha no podría quedarse en el mismo mundo que su hijo, aunque consiguiera poner en paz sus dos versiones. Para que Bruce Wayne viva se tiene que alterar la línea cronológica y por lo tanto los padres tienen que morir al cambiar la historia. Martha decide morir antes, puesto que su versión de Joker hace imposible la mínima posibilidad de encontrarse con su hijo. Por eso, tras una lucha interna grita «el mundo está $l o c o »^{26} \mathrm{y}$ se tira por un precipicio. Con esto, se acaba la obra y Martha se posiciona matando al Joker justo después de pedirle a Thomas que haga todo lo posible para recuperar la vida de Bruce. Y así Batman y Joker consiguen burlarse de la sociedad volviendo a la maternidad, consiguiendo la venganza absoluta que es el retorno al inicio.

Y aún hay un elemento importante que no se puede pasar por alto. En todas las versiones de estos personajes, el Joker considera a Batman un igual en la locura - en los términos planteados de locura de la realidad-, aunque el Murciélago se niega a aceptarlo. Esto se puede ver especialmente en Asilo Arkham, ${ }^{27}$ un cómic pseudopsicodélico que trata el interior del sanatorio y la incursión de Batman en el mundo de locura que representa el Joker. En la imagen final de Asilo Arkham, el Joker se despide de Batman diciéndole que ese siempre será su hogar. ${ }^{28} \mathrm{Y}$ con esta imagen de igualdad en la locura de la realidad, podemos despedirnos del imaginario que revolucionan Thomas y Martha Wayne en El caballero de la veng anza. Después de la ruptura presente en este cómic entendemos todavía más la imagen final de Asilo Arkham, y comprendemos, de forma casi dolorosa, lo que intenta chillarnos el bufón de Martha Wayne al final de El caballero de la venganza.

\section{Conclusiones}

A lo largo de la lectura de El caballero de la venganza hay elementos de los personajes clásicos que se reproducen, pero hay muchos otros que se han reelaborado para dar cabida a una representación mucho más real y humana, en el sentido más cruel de la palabra. En la obra se observa una circularidad, donde todo empieza y acaba con la maternidad y la implicación social. El Joker, en todas sus versiones, es un ser «peligrosamente humano $»^{29}$ pero aquí concretamente lo es todavía más; de la misma manera, representa de una forma más realista, si cabe, la locura de la realidad.

Hemos partido del análisis intrínseco de la obra para estudiarla a partir de las interpretaciones del personaje del Joker al mismo tiempo que se ha tenido en cuenta las

\footnotetext{
26 Azzarello B. y Risso, E. Op. cit.

27 Morrison, G. y McKean, D. Batman: Asilo Arkham. Barcelona, ECC Ediciones, 2016 [1989].

${ }^{28} \mathrm{I}$ dem.

${ }^{29}$ Navarro Páez, J. Op. cit., p. 97.
} 
aportaciones de Valencia y Witting para tener una visión mucho más actualizada del personaje. Es cierto que el cómic está formado por más personajes aparte del Joker de Martha Wayne, pero este es el más interesante por la renovación que aporta a la tradición de la figura y sus circunstancias. También hemos trazado unas pinceladas para un examen incipiente de Batman, dejando claro que son sugerencias para un personaje que merecería, sin duda, un estudio propio.

Hemos constatado que lo más esencial del Joker de Martha parte de la distinción con la tradición: la maternidad y la locura de la realidad. La primera función se encarga de construir un/a protagonista que rompe de forma magistral con la heteronormatividad para formarse, desde la colectividad, con un estilo radicalmente individual. La maternidad permite concebirla desde una visión radicalmente real, puesto que es un elemento que no tenía cabida en la representación tradicional y que conecta al Joker con un lado más humano y, al mismo tiempo, cruel. La segunda función nos ha abierto un espacio específico para entender la posición de Martha en un campo político y social totalmente renovado. Las repercusiones de tal inserción nos han llevado a comprender la importancia del personaje y la relación que comparte con otras obras gráficas y fílmicas. La locura de la realidad representa una visión del mundo excéntrica y divergente, que separa al Joker del imaginario del bufón para convertirlo en un ser nuevo y ambiguo.

Lo que es esencial remarcar aquí es que, a pesar de las grandes implicaciones que presenta, este personaje es una creación que nace y muere en esta obra. Es cierto que al ser una historia autoconclusiva se da la oportunidad de crear una figura única que no se explote en el futuro, como pasa con muchas en la industria; pero, al mismo tiempo, da la sensación de ser una protagonista cuya importancia, después de este breve momento de gloria, quedará escondida entre tanto personaje masculino. Son muchos los motivos que puede haber detrás de la elección, pero lo que es innegable es que el hecho de que muera al final de la obra le da un dramatismo y una realidad que de otra forma no podría tener. El Joker de Martha Wayne nace por un motivo muy claro, y decide morir por el mismo motivo. La propia historia del cómic la obliga a la desaparición; la línea temporal va a reestablecerse y ella tiene que dejar lugar al Batman de Bruce Wayne, pero además decide saltar por el precipicio y morir. Es una elección propia, dirigida, sin duda, por elementos sociales; y, por ende, inevitable. En parte arbitraria y, al mismo tiempo, necesaria: quizá como su misma creación. 


\section{BIBLIOGRAFIA Y FILMOGRAFÍA}

Azzarello B. y Risso E. El caballero de la venganza. Barcelona, ECC Ediciones, 2012.

Díez Balda, M. A. La imagen de la mujer en el cómic: Cómic feminista, cómic futurista y de ciencia-ficción. Universidad de Salamanca, Salamanca, 2004. Disponible en https://www.amites.org/sites/default/files/pdf/publicaciones/antonia diez balda 2004.pdf

Eilish, B. «Bad guy», en When We All Fall Asleep, Where Do We Go? [CD]. Los Ángeles, Interscope Records, Darkroom Records, 2019.

Finger, B. «El hombre tras la Capucha Roja», en Joker: Pura maldad. Barcelona, ECC Ediciones, 2017.

Moore, A. y Bolland, B. Batman: la broma asesina. Barcelona, ECC Ediciones, 2009 [1988].

Morrison, G. y McKean, D. Batman: Asilo Arkham. Barcelona, ECC Ediciones, 2016 [1989].

Navarro Páez, J. ¿¿Quieres saber cómo me hice estas cicatrices? Análisis autobiográfico del Joker [Trabajo de Grado]. Pontificia Universidad Javeriana, Bogotá, 2014. Disponible en https://repository.javeriana.edu.co/handle/10554/14775

Nolan, C. El caballero oscuro [film]. Coproducción Estados Unidos-Reino Unido, Warner Bros / Legendary Pictures, 2008. Guion de Christopher Nolan, David S. Goyer y Jonathan Nolan.

Nolan, C. El caballero oscuro: La leyenda renace [film]. Coproducción Estados Unidos-Reino Unido, Warner Bros / Legendary Pictures, 2012. Guion de Christopher Nolan y Jonathan Nolan.

Phillips, T. Joker [film]. Estados Unidos, Warner Bros, 2019. Guion de Todd Phillips y Scott Silver.

Rivière, J. La femineidad como máscara. Athenea Digital, 2007, pp. 219-226. Traducción de Adriana Velásquez y María Ponce de León. Disponible en http:// psicologiasocial.uab.es/athenea/index.php/atheneaDigital/article/view/374/335 
Segura Jaubert, J. M. «De Derrida a Bajtín: Deconstruyendo la Figura Heroica de Batman y su antagonista el Joker, y la relación de este último con la Historia de la Risa», 2011. Disponible en https://www.academia.edu/3796361/De Derrida a Bajtin Deconstruyendo la figura heroica de Batman y su antagonista el Joker y la conexión de este último con la Historia de la Risa

— «E1 Joker y su reescritura: desde el Tarot a The Dark Knight». Tebeosfera, 2. ${ }^{\text {a }}$ época, n. ${ }^{\circ} 10$ (2012). Disponible en: https://www.tebeosfera.com/documentos/ el joker y su reescritura desde el tarot a the dark knight.html

Valencia, S. «Transfeminismo(s) y capitalismo gore», en Transfeminismos: Epistemes, fricciones y fujos. Editorial Txalaparta, 2013, pp. 109-117.

Witting, M. «El pensamiento heterosexual», en El pensamiento heterosexual y otros ensayos. Barcelona y Madrid, Egales, 2010, pp. 45-57. Traducción de Javier Sáez y Paco Vidarte. 